\title{
ANALISIS AERODINAMIKA PADA BODI MOBIL HEMAT ENERGI LINTANG SAMUDRA MENGGUNAKAN METODE COMPUTATIONAL FLUID DYNAMICS
}

\author{
Bagus Wahyu Prastyo*, Imam Syafa'at dan Muhammad Dzulfikar \\ Jurusan Teknik Mesin, Fakultas Teknik, Universitas Wahid Hasyim \\ Jl. Menoreh Tengah X/22, Sampangan, Semarang 50236, Indonesia. \\ *Email: baguswprastyo15@gmail.com
}

\begin{abstract}
Abstrak
Aerodinamika kendaraan merupakan bentuk pergerakan aliran udara yang memberi pengaruh atau menyebabkan gaya kepada benda saat bergerak dengan kecepatan tertentu. Ada beberapa cara untuk mengetahui bentuk aerodinamika kendaraan. Pertama yaitu melakukan eksperimen dengan memasukkan kendaraan pada terowongan angin. Cara kedua yaitu menggunakan software CFD (Computational fluid dynamic). Dengan metode CFD peneliti dapat membuat berbagai bentuk desain tanpa mengeluarkan biaya tambahan. Penelitian ini bertujuan untuk mengetahui aerodinamika serta nilai Drag coefficient (CD) dan Lift coefficient (CL) pada bodi mobil Lintang Samudra. Simulasi dilakukan pada 4 kecepatan aliran udara yaitu 40, 50,60 dan $70 \mathrm{~km} / \mathrm{h}$. Simulasi menggunakan model turbulensi $\mathrm{k}-\varepsilon$ dengan intensitas $5 \%$, model tersebut dipilih karena memiliki tingkat error terkecil terhadap validasi dari jurnal simulasi Bammidi dan Murty (2014) sebesar 0,13\%. Didapatkan hasil bodi Lintang Samudra 1 memiliki nilai CD $=0,07598-0,07025$ dan $C L=(-0,00800)-(-0,00837)$ Pada bodi Lintang Samudra 2 memiliki nilai $C D=0,072451$ - 0,067020 dan $C L=0,001395-0,000949$. Terdapat perbedaan bentuk aliran fluida pada bodi Lintang Samudra Idan bodi Lintang Samudra 2. Jadi bodi kedua lebih aerodinamis dari bodi pertama.
\end{abstract}

Kata kunci: aerodinamika, bodi, CFD, drag, lift.

\section{PENDAHULUAN}

Aerodinamika berasal dari dua suku kata yaitu aero dan dinamika. Aero memiliki arti sebagai udara dan dinamika sebagai pergerakan, jadi aerodinamika bisa di artikan sebagai pergerakan aliran udara yang memberi pengaruh atau menyebabkan gerak kepada benda saat bergerak dengan kecepatan tertentu. CFD merupakan salah satu cara untuk mengetahui bentuk aerodinamika suatu benda dengan bentuk tertentu. Dalam penelitiannya Jatmiko (2015) melakukan Analisa pola aliran pada bodi Mobil Esemka Rajawali Standar dan modifikasi. Validasi dilakukan dengan membandingkan hasil simulasi dan perhitungan analitis pada tekanan yang terjadi dengan persamaan Bernoulli dengan selisih tekanan atau error $1,16 \%$. Penelitian dilakukan pada kondisi steady dengan mengatur kecepatan aliran udara masuk sebesar 11,19 , dan $27 \mathrm{~m} / \mathrm{s}$. hasil simulasi nilai Drag coefficient dan lift

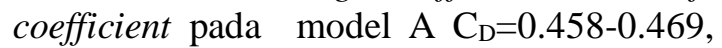
dan model $\mathrm{B} \mathrm{C}_{\mathrm{D}}=0.389-0.405, \mathrm{C}_{\mathrm{L}}=0.195$ 0.199 .

Yusuf dan Utomo (2015) dalam penelitian menyimulasikan mobil hemat bahan bakar Antawirya dan konsep 2 dengan metode Validasi jurnal penelitian backward- facing step. Model turbulensi k-epsilon hasil yang eror terkecil pada model aliran realizable sebesar 3,96\%. Simulasi dilakukan pada 6 kecepatan: $10 \mathrm{Km} / \mathrm{j}$ hingga $60 \mathrm{Km} / \mathrm{j}$ dengan perbedaan $10 \mathrm{Km} / \mathrm{jam}$. Setelah dilakukan simulasi, Konsep 2 memiliki CD yang lebih rendah dibandingkan konsep 1 pada kecepatan $60 \mathrm{Km} / \mathrm{j}$ penurunan terbesar bernilai $45,6 \%$. Dalam penelitiannya Jhon dan Utomo (2017) melakukan simulasi CFD Body Antawirya Turangga Veda 1 dan 2. Dengan Validasi menggunakan metode perbandingan Drag coefficient dari simulasi Ahmed body banga $d k k$. (2015). Menggunakan model turbulensi $k-e$, realizable dengan 4 sudut serang fluida dengan hasil eror 0\%-4\%. Simulasi pada desain Antawirya Turangga Veda I dan II menggunakan 4 kecepatan aliran udara yaitu 40,50 , 60 dan $70 \mathrm{Km} / \mathrm{j}$. Hasil dari simulasi menunjukkan penurunan pada nilai Drag coefficient Antawirya Turangga Veda 2 sebesar $19 \%$ dari desain turangga veda1.

\section{DASAR TEORI}

Aliran udara

Ada beberapa aliran udara pada kendaraan yaitu aliran udara eksternal dan 
internal. Aliran udara internal adalah aliran udara yang ada di dalam kendaraan, jadi aliran udara pada pendinginan mesin dan aliran pada pengemudi termasuk ke dalam aliran ini. Aliran udara eksternal adalah aliran udara pada luar kendaraan seperti gambar 1 .

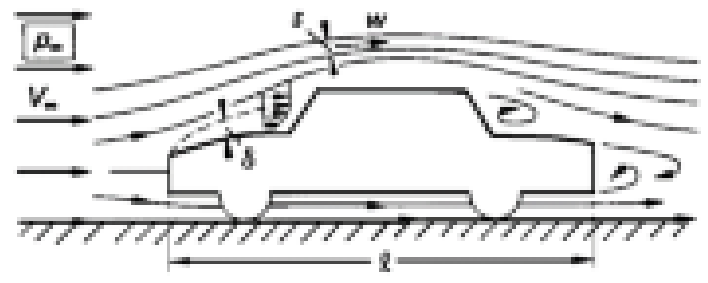

Gambar 1. Aliran di sekitar kendaraan (Hucho, 1998)

\section{Gaya-Gaya Eksternal Kendaraan}

Pada saat kendaraan melaju dengan kecepatan tertentu, maka kendaraan akan mengalami gaya dan juga momen yang di sebabkan oleh aliran udara yang menerpa, untuk nilai coefficient lift dan coefficient drag menurut Hucho (1998) dapat dihitung dengan persamaan:

$$
\begin{aligned}
C_{L} & =\frac{L}{\frac{\rho}{2} V_{\infty}^{2} A_{L}} \\
C_{D} & =\frac{D}{\frac{\rho}{2} V_{\infty}^{2} A_{D}}
\end{aligned}
$$

$$
\begin{aligned}
& \text { Dimana }: \mathrm{D}: \text { Gaya Drag }(\mathrm{N}) \\
& \mathrm{C}_{\mathrm{D}}: \text { Coefficient drag } \\
& \mathrm{L}: \text { Gaya lift }(\mathrm{N}) \\
& \mathrm{C}_{\mathrm{L}}: \text { coefficient lift } \\
& \mathrm{V}: \text { kecepatan udara }(\mathrm{m} / \mathrm{s}) \\
& \rho: \text { Densitas Udara }\left(\mathrm{kg} / \mathrm{m}^{3}\right) \\
& A_{L}: \text { luas area drag }\left(\mathrm{m}^{2}\right) \\
& A_{D}: \text { luas area lift }\left(\mathrm{m}^{2}\right)
\end{aligned}
$$

\section{ANSYS}

ANSYS merupakan sebuah program $\mathrm{CAE}$ (computer aided engineering) yang pertama kali didirikan tahun 1970. Workbench 16.0 merupakan gabungan dari beberapa gabungan analisis system yang disediakan oleh ANSYS. Secara umum analisis yang utama yaitu fluid, structural, elektronik dan systems engine. Untuk analisis fluid sendiri ada beberapa jenis yang dapat di pilih yaitu fluid flow-blow molding (polyflow), fluid flow-exstruion (polyflow), fluid flow (CFX), fluid flow (fluent), fluid flow (polyflow).

\section{METODOLOGI}

Analisis dilakukan dengan melakukan persiapan alat, bahan dan prosedur simulasi antara lain sebagai berikut:

\section{Alat dan Bahan}

Alat yang digunakan untuk penelitian adalah komputer dengan spesifikasi pada tabel 1. Penelitian ini menggunakan software metode elemen hingga Ansys 16.

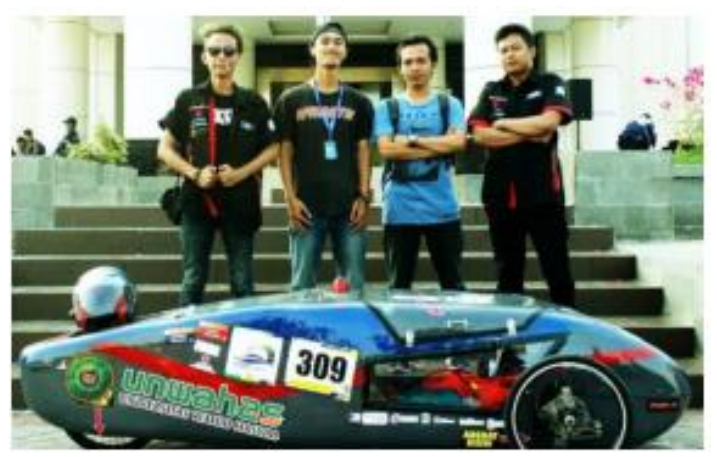

Gambar 2 .Mobil lintang samudra desain pertama untuk lomba

Bahan yang digunakan untuk penelitian adalah desain bodi lintang samudra pertama seperti pada gambar 2 dan juga bodi yang diajukan untuk tahun depan. Desain dibuat dengan software Autodesk Inventor yang kemudian diubah formatnya ke IGES.

Perbedaan bentuk bodi pertama dan kedua terletak pada tinggi bodi tersebut seperti gambar 3, untuk bodi pertama memiliki tinggi $60 \mathrm{~cm}$ dan bodi kedua memiliki tinggi $70 \mathrm{~cm}$. Penambahan tinggi dilalukan karena hasil evaluasi lomba 2019, bodi lintang samudra 1 terdapat kekurangan pada bagian sudut pandang.

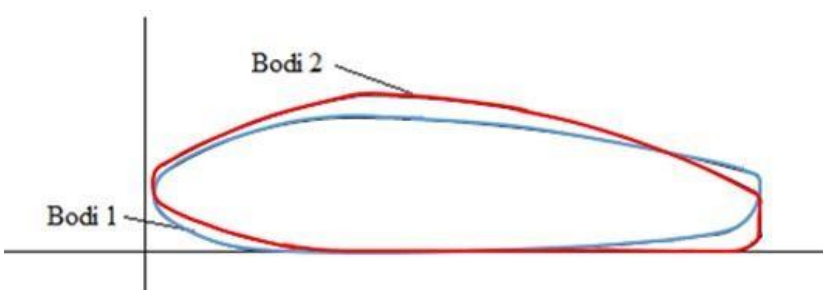

Gambar 3. Perbedaan bodi 1 dan 2

\section{Prosedur Simulasi}

Simulasi Fluid Flow (CFX) ini memiliki beberapa masukan yang wajib di penuhi untuk menjalankan program. seperti pada gambar 4. 


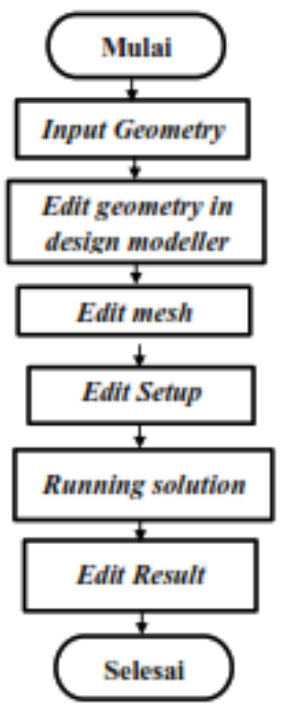

Gambar 4. alur simulasi

\begin{tabular}{|c|c|c|}
\hline \multirow[t]{2}{*}{ 日 } & \multicolumn{2}{|l|}{ Details of Enclosure1 } \\
\hline & Enclosure & Enclosure1 \\
\hline & Shape & Bor \\
\hline & Number of Planes & 0 \\
\hline & Cushion & Non-Uniform \\
\hline & $\square$ FO1, Cushion $+X$ value $(>0)$ & $3 m$ \\
\hline & $\square$ FD2, Cushion $+Y$ value $\mid>0\}$ & $3 \mathrm{~m}$ \\
\hline & $\square$ FD3, Cushion $-Z$ value $(>0)$ & $3 \mathrm{~m}$ \\
\hline & $\square$ FD4, Cushion $X$ value $\mid>0$ & $3 \mathrm{~m}$ \\
\hline & $\square$ FD5, Cushion - $\mathrm{Y}$ value $(>0)$ & $0,3 \mathrm{~m}$ \\
\hline & $\square$ FD6, Cushion $-Z$ value $\mid>0$ ) & $3 \mathrm{~m}$ \\
\hline & Target Bodies & All Eodies \\
\hline
\end{tabular}

Gambar 5. Ukuran terowongan angin

Pertama memasukkan desain dan membuat terowongan angin dengan ukuran seperti pada gambar 5 dan hasilnya pada gambar 6 .

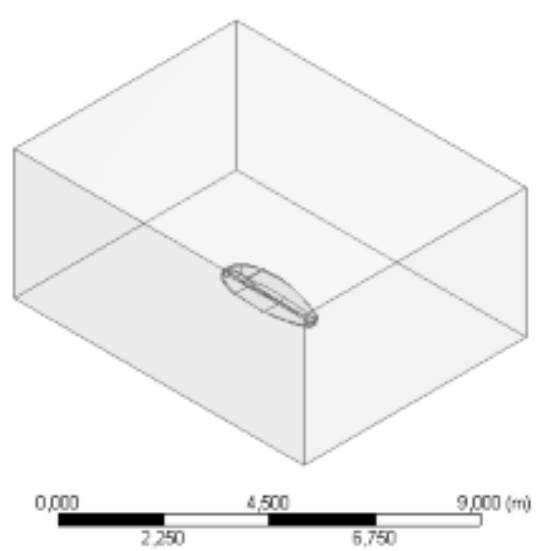

(a.)

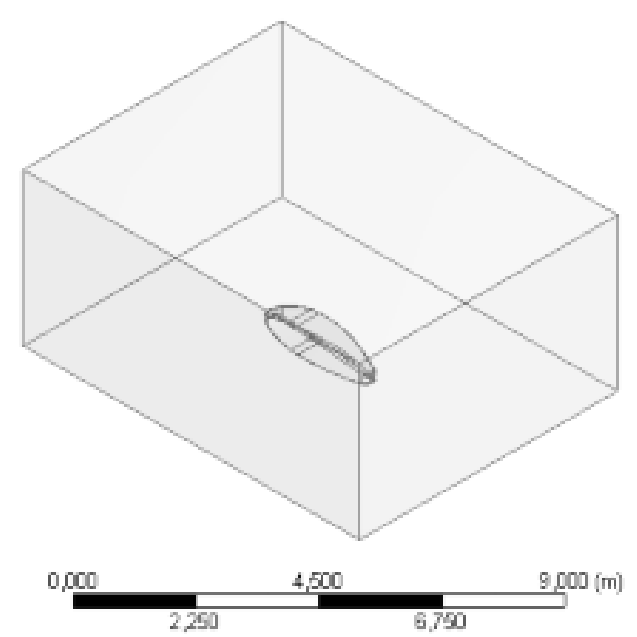

(b.)

Gambar 6. Bodi dengan terowongan angin pada design modeler (a.) bodi 1 (b.) bodi 2.

Kedua masuk ke proses mesh, untuk setup proses mesh dapat di lihat pada tabel 1 .

Tabel 1. Detail mesh

\begin{tabular}{lllc}
\hline No & $\begin{array}{c}\text { Details of } \\
\text { mesh }\end{array}$ & \multicolumn{1}{c}{ Pilihan } & Size \\
\hline 1 & Advanced size & Proximity and & - \\
& function & curvature & \\
2 & Smoothing & medium & - \\
3 & sizing & box : - Max & $90 \mathrm{~mm}$ \\
& & - Min & $45 \mathrm{~mm}$ \\
& & -Proximity min & $20 \mathrm{~mm}$ \\
4 & Face sizing & Bodi: - Max & $45 \mathrm{~mm}$ \\
& & - Min & $20 \mathrm{~mm}$ \\
5 & Inflantion & Max layer & 4 \\
\hline
\end{tabular}

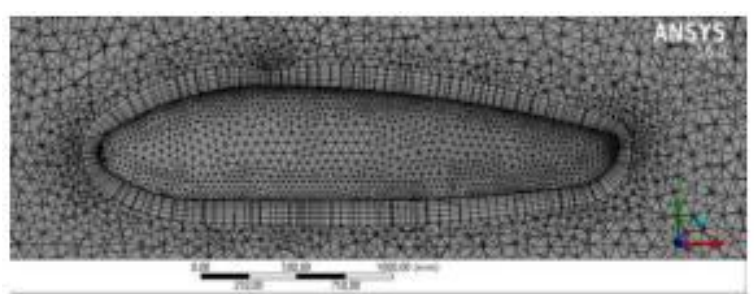

(a.)

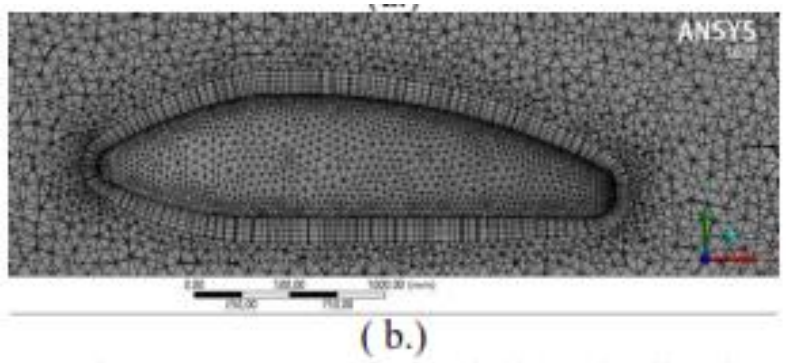

Gambar 7. Proses mesh simulasi (a.) bodi 1 (b.)bodi 2 
Hasil proses mesh dapat dilihat pada gambar 7. Langkah ke 3 proses SETUP, untuk detail parameter input dapat di lihat pada tabel 2.

Tabel 2. Detail set up

\begin{tabular}{|c|c|c|c|}
\hline No & $\begin{array}{l}\text { Detall } \\
\text { setup }\end{array}$ & Pilit & \\
\hline 1 & Material & air ideal gas & $25^{\circ} \mathrm{C}$ \\
\hline 2 & $\begin{array}{l}\text { Relative } \\
\text { pressure }\end{array}$ & $1 \mathrm{~atm}$ & - \\
\hline 3 & Turbulance & $\begin{array}{l}\text { - K-epsilon } \\
\text {-intensity }\end{array}$ & $\begin{array}{l}\text { medium } \\
(5 \%)\end{array}$ \\
\hline 4 & inlet & $\begin{array}{l}\text { - velocity } \\
\text { - turbulance }\end{array}$ & $\begin{array}{l}40 \mathrm{~km} / \mathrm{h} \\
\text { (intensity }= \\
5 \%)\end{array}$ \\
\hline 5 & outlet & pressure & $0 \mathrm{~Pa}$ \\
\hline 6 & $\begin{array}{l}\text { wall } \\
\text { bottom }\end{array}$ & $\begin{array}{l}\text { - no slip wall } \\
\text { - noughness }\end{array}$ & $\begin{array}{l}(-40 \mathrm{~km} / \mathrm{h}) \\
\text { Smooth } \\
\text { wall }\end{array}$ \\
\hline 7 & wall side & free slip wall & - \\
\hline 8 & wall top & free slip wall & - \\
\hline 9 & bodi & $\begin{array}{l}\text { - no slip wall } \\
\text { - roughness }\end{array}$ & $\begin{array}{l}\text { smooth } \\
\text { wall }\end{array}$ \\
\hline
\end{tabular}

\section{Metode Penelitian}

Penelitian ini memiliki langkahlangkah yang harus di lalui. Seperti pada gambar 8. Hasil perhitungan di bandingkan dengan jurnal acuan validasi simulasi Bammidi dan Murty (2014). Apabila hasil error lebih dari $5 \%$, maka kembali lagi ke proses setup, setelah hasil perbandingan dibawah 5\% baru validasi telah selesai dilakukan.

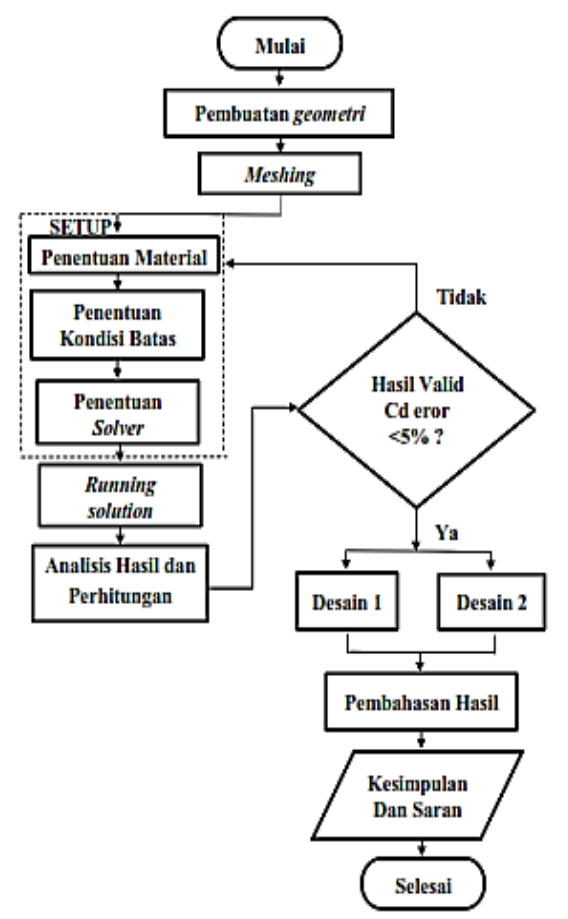

Gambar 8. diagram alir simulasi

\section{HASIL DAN PEMBAHASAN}

Hasil Simulasi Validasi

Validasi dilakukan dengan membandingkan hasil Drag coefficient simulasi dengan jurnal acuan dengan error kurang dari $5 \%$. Setelah itu langkah simulasi dengan error terkecil digunakan pada desain bodi Lintang Samudra. dan diperlihatkan pada tabel 3 .

Tabel 3. Error simulasi

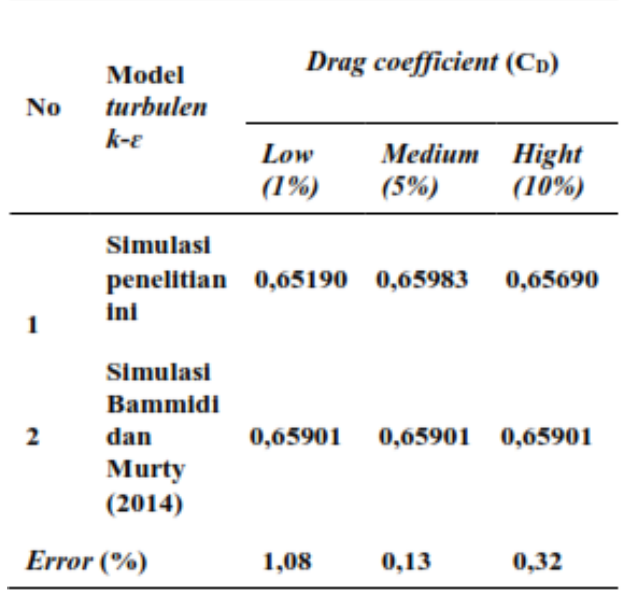

Setelah error dihitung, didapatkan hasil error paling sedikit adalah model $\mathrm{k}-\varepsilon$ yang memiliki tingkat turbulensi medium intensity $(5 \%)$ dengan nilai error $0.13 \%$. Maka digunakan sebagai model turbulensi yang digunakan untuk simulasi bodi Lintang Samudra.

\section{Hasil simulasi Bodi Lintang Samudra}

Langkah simulasi yang sama dengan acuan validasi digunakan juga untuk bodi Lintang Samudra 1 dan 2. Dengan 4 variasi kecepatan 40-70 km/h. Pada gambar 9 . diperlihatkan gaya drag yang meningkat tiap bertambahnya kecepatan fluida udara, hal ini dikarenakan besar gaya drag berbanding lurus dengan kecepatan.

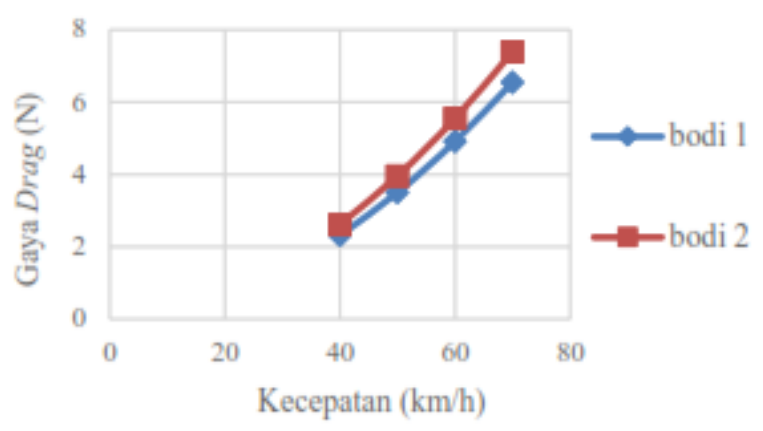

Gambar 9. perbandingan gaya drag bodi 1 dan 2 
Gaya drag pada bodi Lintang Samudra 2 lebih besar dibanding bodi 1. Akibat penambahan tinggi kendaraan menyebabkan bertambahnya luas area pada bodi Lintang Samudra ke 2 sehingga gaya yang di terima lebih besar.

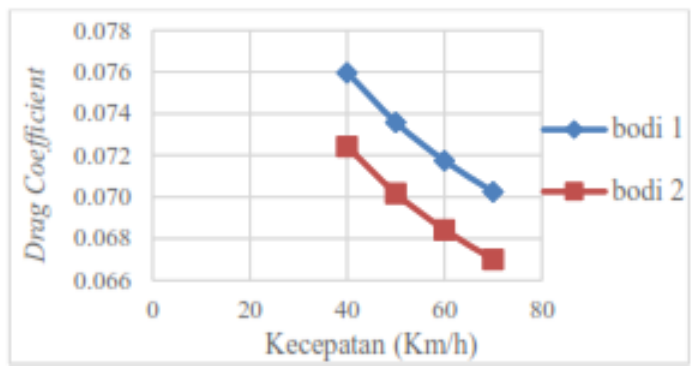

Gambar 10. perbandingan Drag coefficient bodi 1 dan 2

Pada gambar 10. terlihat nilai Drag coefficient yang semakin bertambah seiring penurunan kecepatan. Hal ini dikarenakan koefisien gesek udara yang semakin kecil seiring bertambahnya kecepatan. Drag coefficient pada bodi Lintang Samudra 1 memiliki nilai lebih besar dari bodi Lintang Samudra ke 2. Jadi Drag coefficient bodi Lintang Samudra ke 2 lebih baik dari bodi 1.

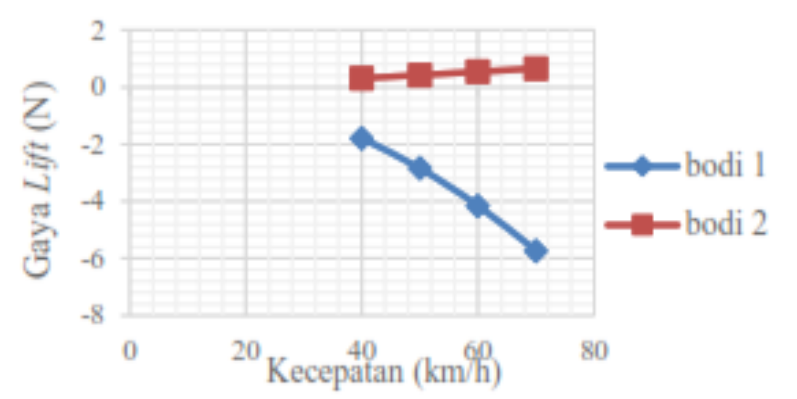

Gambar 11. perbandingan lift bodi 1 dan 2

Pada gambar 11. gaya lift semakin besar seiring dengan pertambahan kecepatan fluida udara. Gaya lift pada bodi Lintang Samudra 1 memiliki sifat negatif, untuk bodi Lintang Samudra 2 memiliki sifat gaya lift positif.

Pada gambar 12. diketahui nilai lift coefficient semakin menurun seiring pertambahan kecepatan fluida udara. Untuk bodi 1 memiliki nilai lift coefficient negatif sehingga menambah berat bodi. Untuk bodi ke 2 lift coefficient positif sehingga dapat mengurangi berat kendaraan. Jadi bodi yang lebih baik digunakan adalah bodi Lintang Samudra 2 bodi 2 pada kecepatan $60 \mathrm{~km} / \mathrm{h}$ Pada gambar 13. terlihat perbedaan bentuk aliran yang menerpa bodi. Pada bodi Lintang Samudra 1 ketika udara melewati bagian depan, aliran udara mulai melambat di tunjukkan dengan warna hijau. Kemudian aliran terpecah dan kecepatannya meningkat terlihat dari warna vektor yang kemerahan. Pada bagian bawah warna vektor kecepatan lebih merah dari bagian atas, hal ini berarti aliran udara yang mengalir lebih cepat bagian bawah

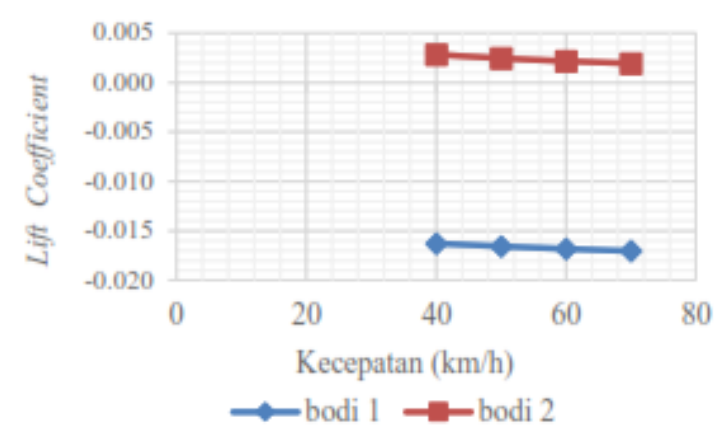

Gambar 12. Perbandingan lift coefficient bodi 1 dan 2

Untuk bodi Lintang Samudra 2 ketika udara melewati bagian depan bentuknya menyerupai bodi 1 tetapi vektor kecepatan yang berwarna hijau lebih luas. Kemudian aliran terpecah dan kecepatan meningkat sama seperti bodi 1 . Tetapi untuk bodi ke 2 aliran yang mengalir di bagian atas lebih cepat dari bagian bawah terlihat dari warna yang lebih merah.

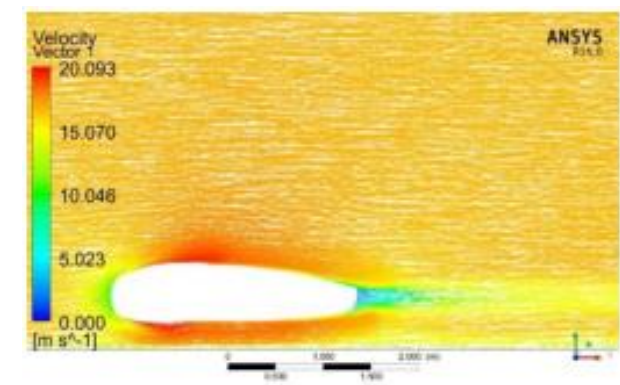

(a.)

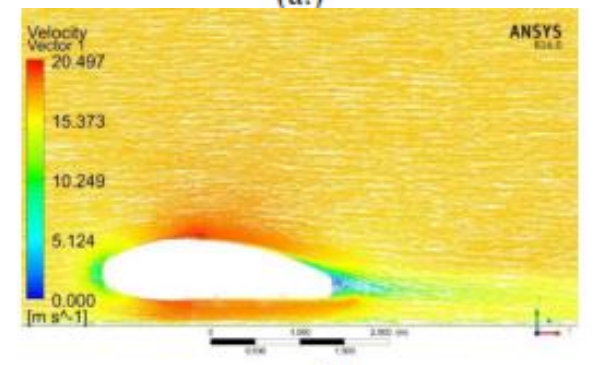

(b.)

Gambar 13. Vektor kecepatan (a.) bodi 1 (b.) 


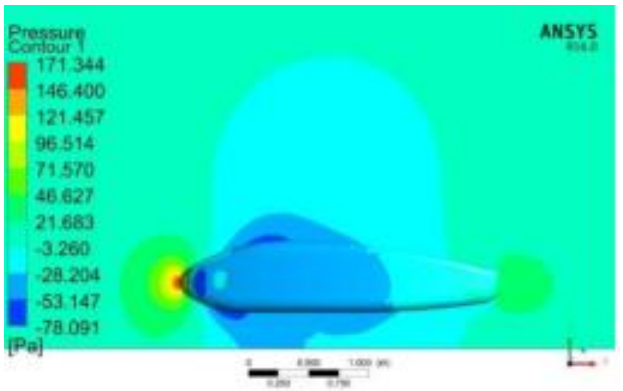

(a.)

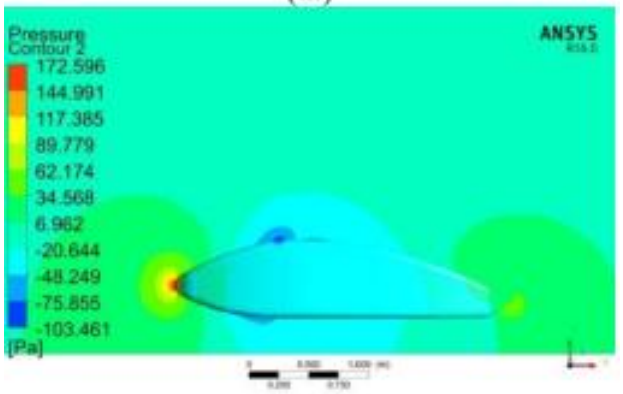

(b.)

Gambar 14. Kontur tekanan (a.) bodi 1 (b.) bodi 2 pada kecepatan $60 \mathrm{~km} / \mathrm{h}$

Pada gambar 14. terlihat perbedaan bentuk kontur tekanan yang terjadi akibat dari perbedaan aliran fluida dan kecepatan. Pada bodi Lintang Samudra 1 kontur tekanan pada bagian depan memiliki luas yang lebih kecil dari bodi ke 2,. Untuk kontur bagian tengah bodi 1 memiliki bentuk kontur yang lebih luas dari bodi 2 . Untuk bagian belakang bodi ke 2 memiliki kontur tekanan yang lebih luas dari bodi 1. Perbedaan tekanan pada bagian depan dan belakang ini yang menyebabkan gaya drag dan perbedaan tekanan pada bagian bawah bodi dengan bagian atas menyebabkan gaya lift.

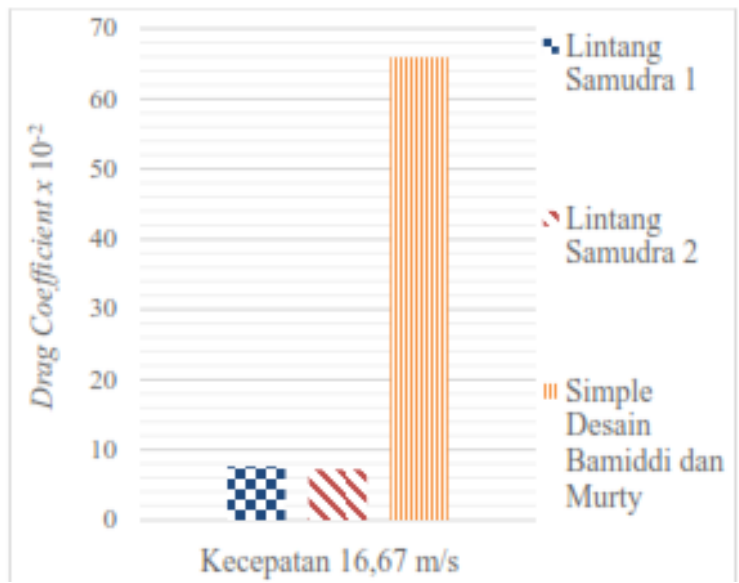

Gambar 15. perbandingan $C_{D}$ Lintang Samudra 1 dan 2 dengan Desain Bamidi dan Murty (2014)
Pada gambar 15. terlihat perbedaan nilai Dag coefficient bodi Lintang samudra dibandingkan dengan bodi Simulasi Bammidi dan Murty (2014) pada kecepatan fluida 16,67 $\mathrm{m} / \mathrm{s}$ atau $60 \mathrm{~km} / \mathrm{h}$ memiliki nilai $\mathrm{C}_{\mathrm{D}}=$ 0,65901 . Sedangkan untuk bodi Lintang Samudra $1=0,07174$ dan bodi Lintang Samudra $2=0,06842$. Jadi nilai $C_{D}$ bodi lintang samudra lebih baik dari desain Bammidi dan Murty (2014)

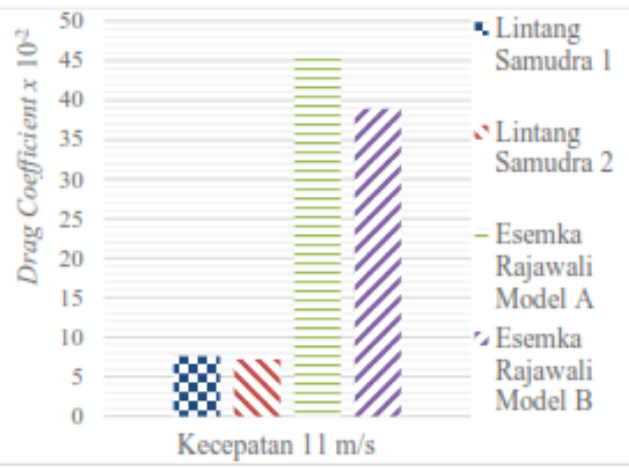

Gambar 16. Grafik perbandingan CD Lintang Samudra 1dan 2 dengan Mobil Esemka

Rajawali (Jatmiko, 2015)

Pada gambar 16. terlihat perbedaan nilai drag coefficient bodi Lintang samudra Dibandingkan dengan bodi Simulasi Jatmiko (2015) mobil Esemka Rajawali pada kecepatan fluida $11 \mathrm{~m} / \mathrm{s}$ atau setara dengan 40 $\mathrm{km} / \mathrm{h}$ memiliki nilai $\mathrm{C}_{\mathrm{D}}=0.458$ untuk model standar dan model modifikasi $C_{D}=0.389$. Sedangkan untuk bodi Lintang Samudra $1=$ 0,07598 dan bodi Lintang Samudra $2=$ 0,07243 . Jadi bodi lintang samudra memiliki nilai Drag coefficient yang lebih baik

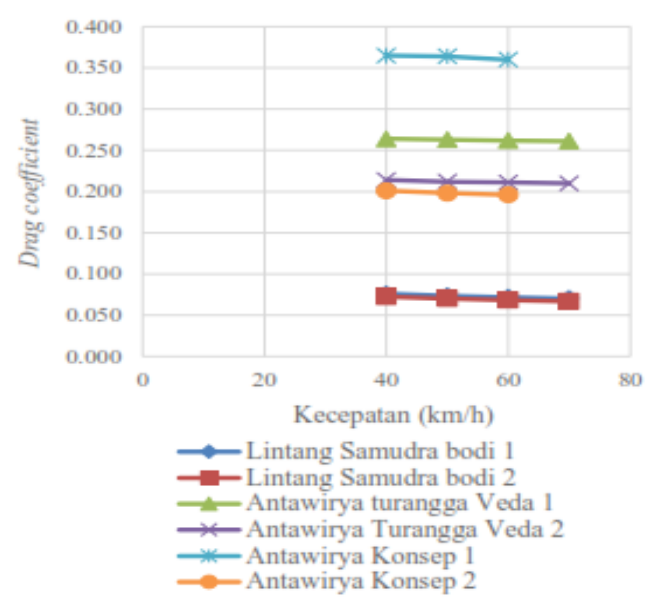

Gambar 17. Grafik perbandingan gaya drag bodi Lintang Samudra, Antawirya Yusuf (2015) dan Antawirya Turangga Veda Jhon (2017). 
Dibandingkan dengan bodi Simulasi Yusuf dan Utomo (2015) mobil hemat bahan bakar Antawirya pada kecepatan $50 \mathrm{~km} / \mathrm{h}$ memiliki nilai $C_{D}=0,364$ untuk konsep 1 dan konsep $2 C_{D}=0,198$. Sedangkan untuk bodi Lintang Samudra $1=0,07358$ dan bodi Lintang Samudra $2=0,07017$. Dibandingkan dengan bodi simulasi Jhon dan Utomo (2017) mobil hemat energi Antawirya residual-sat pada kecepatan $70 \mathrm{~km} / \mathrm{h}$ memiliki nilai $\mathrm{C}_{\mathrm{D}}=$ 0,26 untuk Antawirya Turangga Veda 1 dan Antawirya Turangga Veda $2 \mathrm{C}_{\mathrm{D}}=0,21$. Sedangkan untuk bodi Lintang Samudra $1=$ 0,07025 dan bodi Lintang Samudra $2=$ 0,06700. Dari perbandingan nilai Drag coefficient, bodi Lintang Samudra 2 memiliki nilai yang lebih baik.

\section{KESIMPULAN}

Berdasarkan hasil analisa dari simulasi terhadap desain bodi lintang samudra 1 dan 2 dengan variasi kecepatan 40-70 km/h didapatkan kesimpulan sebagai berikut:

1. Terdapat perbedaan aliran fluida yang terjadi pada bodi 1 dan 2 lintang samudra. Bentuk aliran fluida pada bodi 1 yang melewati bagian bawah terlihat lebih cepat dibanding bagian atas sehingga akibatnya gaya lift yang terjadi memiliki arah ke bawah (-). Sedangkan untuk aliran fluida pada bodi ke 2 aliran udara yang melewati bagian bawah lebih lambat dari yang bagian atas sehingga gaya lift arahnya ke atas.

2. Dalam empat kecepatan yang berbeda didapat nilai drag coefficient dan lift yang berbeda. Pada bodi 1 lintang samudra nilai $C_{D}$ dari kecepatan $40-70$ $\mathrm{km} / \mathrm{h}$ adalah 0,07598- 0,07025. Pada bodi 2 lintang samudra nilai $C_{D}$ dari kecepatan $40-70 \mathrm{~km} / \mathrm{h}$ adalah 0,072451 - 0,067020. Untuk nilai lift coefficient pada bodi 1 lintang samudra nilai $\mathrm{C}_{\mathrm{L}}$ dari kecepatan $40-70$ adalah $(-0,00800)-(-0,00837)$. Untuk nilai lift coefficient pada bodi 2 lintang samudra nilai $\mathrm{C}_{\mathrm{L}}$ dari kecepatan $40-70 \mathrm{~km} / \mathrm{h}$ adalah $0,001395-0,000949$.

\section{DAFTAR PUSTAKA}

Bammidi, R. dan Murty, B. V. R., 2014, AnsysCFX Analysis on a Simple Automobile Design, India, International Journal of Science and Research (IJSR), 2319-7064.

Hucho, W.H., 1998, Aerodynamics of Road Vehicles, Warrendale, United States, SAE International.

Jatmiko, A.W., 2015, Analisa Pola Aliran Pada Bodi Mobil Esemka Rajawali Standar Dengan Esemka Rajawali Modifikasi Menggunakan CFD (Computational Fluid Dynamic) Pada Software Ansys 15.0, Teknik Mesin Universitas Muhammadiyah Surakarta.

Jhon, J. S. dan Tony, S. U., 2017.“Analisis Aerodinamika Body Mobil Hemat Energi Antawirya Residual-Sat Dengan Menggunakan Metode Computational Fluid Dynamics". Universitas Diponegoro, 5-1.

Yusuf , F. I. dan Tony, S. U., 2015."Simulasi Aerodinamika Mobil Hemat Bahan Bakar 'Antawirya' Konsep 2 Menggunakan Metode Computational Fluid Dynamics (CFD)". Universitas Diponegoro, 3-3. 